\title{
Successful Implantation of a Permanent Pacemaker through a Persistent Left Superior Vena cava
}

\author{
Ali H. Al-Sayegh Fawziah Al-Kandari \\ Department of Cardiology, Chest Disease Hospital, Kuwait
}

\section{Key Words}

Persistent left superior vena cava $\cdot$ Pacemaker $\cdot$ Right heart catheterization

\begin{abstract}
We present a case of successful implantation of a permanent pacemaker through an unusual course of a persistent left superior vena cava (PLSVC). A young male patient presented with symptomatic bradycardia and a heart rate of 35 beats per minute. The pacing lead was introduced through the standard left subclavian vein approach and was found to pass through an unusual course that was suspected to be a PLSVC. The lead was further advanced to the right atrium and positioned successfully in the right atrial appendage with excellent short-term and long-term pacing parameters. PLSVC should be suspected whenever the catheter takes an unusual position during central venous catheterization. Most right heart catheterization procedures, including permanent pacemaker implantation, can be safely completed in spite of this anomaly.
\end{abstract}

Copyright $\odot 2002$ S. Karger AG, Base

\section{Introduction}

The presence of a persistent left superior vena cava (PLSVC) in isolation from other congenital heart disease has no significant implication except for procedural purposes such as right heart catheterization or pacemaker insertion [1-3]. In view of the increasing number of central venous procedures that are performed in the setting of intensive care units and cardiac laboratories, we report here an unusual case of a PLSVC that was discovered only during the implantation of a permanent pacemaker. The patient had a successful pacemaker implantation through the PLSVC after the use of simple techniques to verify the continuity of the PLSVC with the right side of the heart.

\section{Case Report}

A 33-year-old male presented with multiple dizzy spells and inappropriate sinus bradycardia. The patient underwent a permanent pacemaker implantation with the use of a single-chamber atrial pacemaker (AAI). Under local anesthesia, a left pectoral incision was made and the central line (peel-away sheath) was introduced into the left subclavian vein. The guide wire was advanced under fluoroscopic imaging and was unexpectedly found to pass over the left ventricular shadow. The presence of a PLSVC was suspected and later confirmed with the advancement of the guide wire into the right atrium through the coronary venous sinus and then to the inferior vena cava. Blood sampling for oxygen saturation and lateral fluoroscopic projectin were also used to rule out the possibility of the guide wire entering

Dr. Ali Al-Sayegh

Department of Cardiology

Chest Disease Hospital, P.O. Box 4082

1304 Safat (Kuwait)

Tel. +965481 7987/+965965 4019, E-Mail dr_alsayeq@hotmail.com
Fax + 41613061234 E-Mail karger@karger.ch www. karger.com

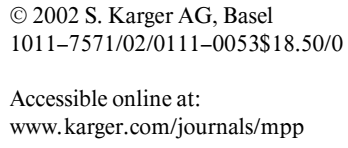




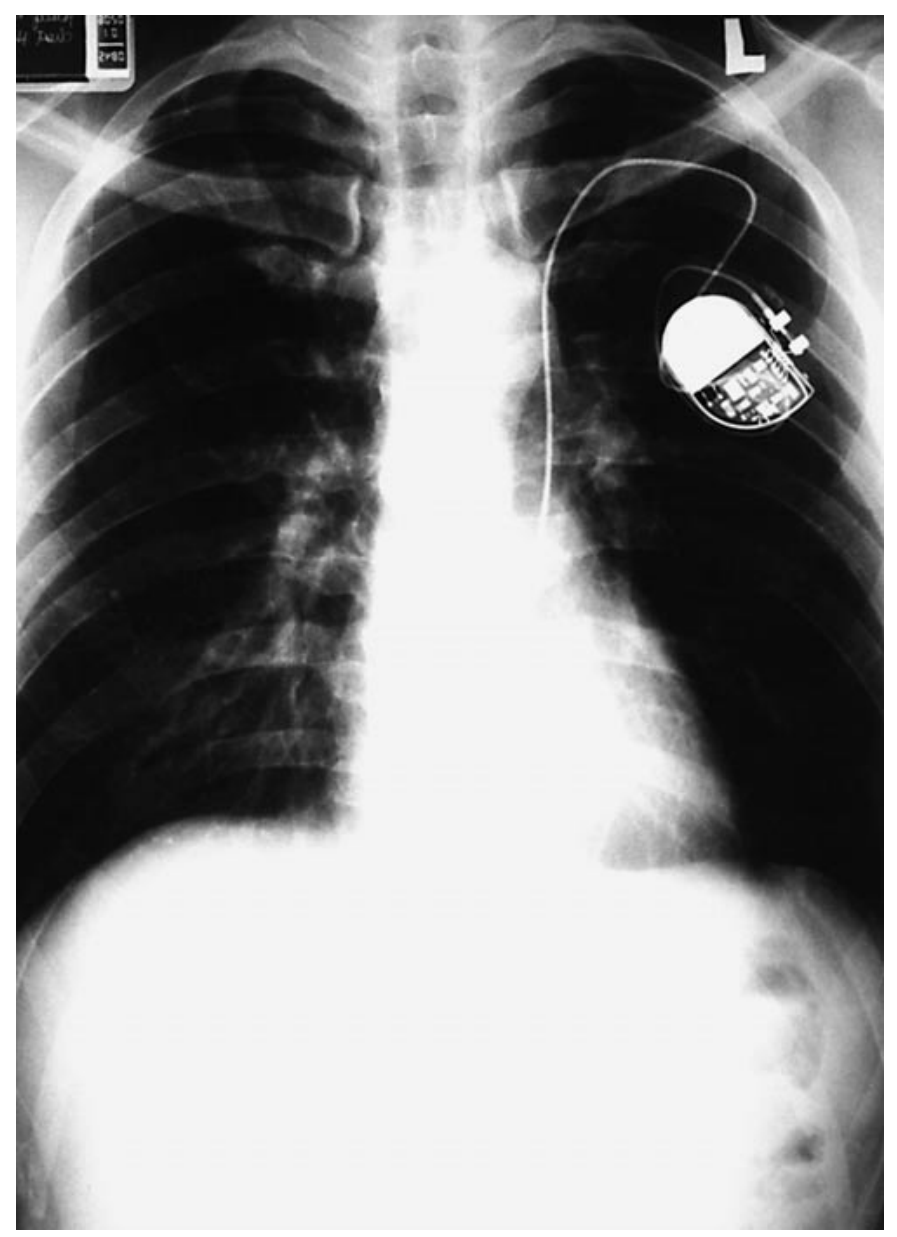

Fig. 1. Chest $x$-ray PA view. Pacing lead passes through left subclavian vein to persistent left superior vena cava, coronary sinus and ending at right atrium.

the aorta. A 5-Fr pacemaker lead was advanced through the sheath to the right atrium cavity. A reshaped stylet with a wider J loop was used to direct the lead to the anteriorly located right atrial appendage. Measurements of the pacing threshold and $\mathrm{p}$ wave amplitude were less than $0.6 \mathrm{~V}$ at a 0.5 -ms pulse width, while the lead impedance was 560 ohms. The patient's follow-up at 12 months showed the stable lead position (fig. 1) and normal pacemaker function.

\section{Discussion}

PLSVC occurs in about $0.3 \%$ of healthy individuals and $4.4 \%$ of patients with congenital heart disease [4]. The right superior vena cava is normally the only connection between the great veins of the upper body and the right atrium (fig. 2a). The right superior vena cava rarely coexists with PLSVC, and the two cavae are bridged with a connecting vein (fig. $2 b$ ). When the right superior vena

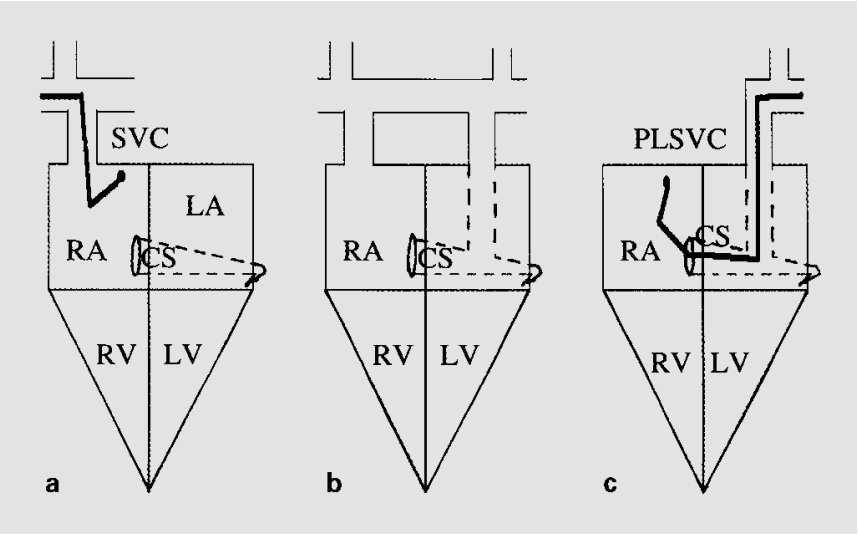

Fig. 2. Schematic diagrams of the three variants of upper body venous connection to the heart. a Pacing wire passes through normal SVC. b Co-existing SVC and PLSVC. c Pacing wire passes through isolated PLSVC. SVC = Superior vena cava; $\mathrm{PLSVC}=$ persistent left superior vena cava; $\mathrm{RA}=$ right atrium; $\mathrm{LA}=$ left atrium; $\mathrm{CS}=$ coronary sinus; $\mathrm{RV}=$ right ventricle; $\mathrm{LV}=$ left ventricle.

cava is absent, PLSVC becomes the only available access to the right atrium from the upper part of the body (fig. 2c).

There are usually no reliable clinical findings to suggest the presence of isolated left-sided superior vena cava; however, it should be suspected whenever a pacemaker lead takes an abnormal course and overlaps with the arterial circulation in the anteroposterior fluoroscopic plane. Failure to recognize the presence of a PLSVC leads to unnecessary repetition of the venous puncturing or even termination of the procedure based on inappropriate interpretation of the lead location. The use of different fluoroscopic projection or even contrast venography when necessary will help to identify the exact catheter location.

In this patient, the standard atrial stylet with a preformed $\mathrm{J}$ loop was too small to reach the right atrial appendage from the coronary sinus in a caudocranial direction. Manual reshaping and sizing of the stylet facilitated the lead positioning. Since part of the lead was wasted through the lengthy course of the coronary sinus, a longer lead of $57 \mathrm{~cm}$ was required to reach the atrial appendage compared to the usual shorter course in the right superior vena cava (fig. 2a). An active fixation lead was chosen rather than the passive fixation lead in order to assure lead stability. Figures $2 \mathrm{a}-\mathrm{c}$ show schematically the different variants of venous anatomy with the lead passing through a normal superior vena cava (fig. 2a) and through a PLSVC (fig. 2c). 
Drainage of PLSVC to the right atrium could rarely occur through an unroofed coronary sinus or directly to the left atrium, leaving part of the pacemaker lead exposed to the systemic arterial circulation. An unroofed coronary sinus is usually associated with central cyanosis due to right-to-left shunting [4] and will preclude the use of the coronary sinus as a proper conduit for permanent pacemaker lead implantation.

The presence of a lead in the coronary sinus as a foreign body carries the theoretical risk of coronary sinus thrombosis. Recently, there is a growing body of data from biventricular pacing studies for the treatment of severe heart failure which confirms the safety of placing permanent pacemaker leads in the coronary sinus [5, 6]. In these studies, more than 200 coronary sinus lead placements were performed in an antegrade direction, i.e. right atrium to coronary sinus. The lower incidence of coronary sinus thrombosis could be explained based on the pres- ence of brisk blood flow in the coronary sinus compared to the other venous structures. Also, the recent advances in lead design with respect to smaller size $(5 \mathrm{Fr})$ and smoother surface are additional factors in the lower incidence of coronary sinus thrombosis.

\section{Conclusion}

PLSVC should be suspected whenever a pacemaker lead passes through an unusual course in the upper venous circulation. Repeating the venous puncture from the same side or from the contralateral side could be avoided when this condition is promptly recognized. Proper verification of pacing lead location and the use of appropriate lead size and type and stylet shaping and sizing make the implantation of permanent pacemakers through a PLSVC feasible and safe.

\section{References}

1 Schelling G, Briegel J, Eichinger K, Raum W, Forst H: Pulmonary artery catheter placement and temporary cardiac pacing in a patient with a persistent left superior vena cava. Intensive Care Med 1991;17:507-508

2 Lai YC, Goh JC, Lim SH, Seah TG: Difficult pulmonary artery catheterization in a patient with persistent left superior vena cava. Anaesth Intensive Care 1998;26:671-673.
3 Leibowitz AB, Halpern NA, Lee MH, Iberti TJ: Left-sided superior vena cava: A not-so-unusual vascular anomaly discovered during central venous and pulmonary artery catheterization. Crit Care Med 1992;20:1119-1122.

4 Perloff JK: The Clinical Recognition of Congenital Heart Disease, ed 4. Philadelphia, Saunders, 1994, pp 703-713.

5 Cazeau S, Leclerq C, Lavergne T, Walker S, Varma C, Linda C, Garrigue S, Kappenberger L, Haywood GA, Santini M, Bailleul C, Daubert JC: Effects of multisite biventricular pacing in patients with heart failure and intraventricular conduction delay. N Engl J Med 2001; 22:873-880.
6 Gras D, Mabo P, Tang T, Luttikuis O, Chatoor $\mathrm{R}$, Pedersen AK, Tscheliessnigg $\mathrm{HH}$, Deharo JC, Puglisi A, Silvestre J, Kimber S, Ross H, Ravazzi A, Paul V, Skehan D: Multisite pacing as a supplemental treatment of congestive heart failure: Preliminary results of the Medtronic Inc. InSync study. Pacing Clin Electrophysiol 1998;21:2249-2255. 